\title{
Treatment of genitourinary syndrome of menopause: the potential effects of intravaginal ultralow-concentration oestriol and intravaginal dehydroepiandrosterone on quality of life and sexual function
}

\author{
Valentina Lucia La Rosa ${ }^{1}$, Michat Ciebiera ${ }^{2}$, Li-Te Lin ${ }^{3}$, Shangrong Fan², Salvatore Butticè ${ }^{5}$, \\ Thozhukat Sathyapalan ${ }^{6}$, Robert Jędra², Patricia Lordelo7, Alessandro Favilli ${ }^{8}$ \\ ${ }^{1}$ Unit of Psychodiagnostics and Clinical Psychology, University of Catania, Catania, Italy \\ ${ }^{2}$ Second Department of Obstetrics and Gynaecology, The Centre of Postgraduate Medical Education, Warsaw, Poland \\ ${ }^{3}$ Department of Obstetrics and Gynaecology, Kaohsiung Veterans General Hospital, Kaohsiung, Taiwan \\ ${ }^{4}$ Department of Obstetrics and Gynaecology, Peking University Shenzhen Hospital, Shenzhen, China \\ ${ }^{5}$ Department of Urology, San Giovanni di Dio Hospital, Agrigento, Italy \\ ${ }^{6}$ Department of Academic Diabetes, Endocrinology and Metabolism, Hull York Medical School, University of Hull, Hull, UK \\ ${ }^{7}$ Bahiana School of Medicine and Public Health, Salvador, Brazil \\ ${ }^{8}$ Section of Obstetrics and Gynaecology, Department of Surgical and Biomedical Sciences, Santa Maria Della Misericordia Hospital, \\ University of Perugia, Perugia, Italy
}

\begin{abstract}
The climacteric is considered a natural phase in a woman's aging process and is defined as the period starting from the decline in ovarian activity until after the end of ovarian function. Genitourinary syndrome of menopause (GSM) is commonly observed in menopausal women and is characterised by a collection of symptoms resulting from changes to the internal and external genitalia as well as the lower urinary tract. Several studies have demonstrated the close association between sexual dysfunction and symptoms related to GSM. Many medications, at different doses, have been studied over the years for the treatment of the symptoms of GSM. More specifically, ultralow-dose intravaginal oestriol and intravaginal dehydroepiandrosterone (DHEA) are reported to improve symptoms, signs, and quality of life of women with GSM, and they are safe owing to their specific local effect. While the dosage and the administration of intravaginal DHEA are well defined, the literature on intravaginal oestriol is less uniform: different doses and times of administration are proposed with different possible combinations with other non-pharmacological therapies, although a more standardised treatment may be necessary. The aim of this review is to summarise the available data about the effects of ultralowconcentration oestriol and intravaginal DHEA on the menopause-related symptoms, quality of life, and sexual function of women affected by GSM.
\end{abstract}

Key words: genitourinary syndrome of menopause, local therapy, oestriol, dehydroepiandrosterone, quality of life, sexuality.

\section{Menopause: physiology or pathophysiology?}

Climacteric is considered a natural phase in a woman's aging process and is defined as the period starting from the decline in ovarian activity until the end of ovarian function. Natural menopause is defined as the permanent cessation of menstrual periods, after 12 months of amenorrhoea without any other pathological or physiological cause. It is characterised by a decrease in ovarian function with a consequent reduction in oestrogen levels. This condition, which involves the whole of the woman's body, has several manifestations: vasomotor symptoms, vulvovaginal atrophy, depression, reduced cognitive function, osteoporosis, and an increased risk of cardiovascular diseases and malignancy [1-4]. Furthermore, it has been highlighted that in postmenopausal women, a higher burden of climacteric symptoms is associated with pelvic organ prolapse and urinary incontinence [5-10].

Vulvovaginal atrophy (VVA) is defined as a progressive, chronic condition that manifests itself as involution of the vulvovaginal mucous membranes and tis- 
sues due to the menopausal drop in oestrogen levels [11-13]. Recently, the term VVA has been replaced by the more scientifically accurate term "genitourinary syndrome of menopause" (GSM) [14, 15].

\section{Genitourinary syndrome of menopause}

GSM is commonly observed in menopausal women and is characterised by a collection of symptoms resulting from changes to the internal and external genitalia as well as the lower urinary tract [14]. Changes in objective and subjective symptoms are present in $25 \%$ to $50 \%$ of all postmenopausal women [16]. In fact, various cohort studies reported a $27 \%$ to $55 \%$ prevalence of GSM in postmenopausal women and estimated that such symptoms persist in $10 \%$ to $25 \%$ of women even after receiving hormonal therapy $[17,18]$. More recent studies show a prevalence of GSM ranging from $50 \%$ to $84 \%$ [19-21], and it may be even higher because symptoms of GSM may also involve premenopausal women with a hypoestrogenic state, such as women with premature ovarian failure, hypothalamic amenorrhoea, surgical menopause, and those who were treated with systemic chemotherapy or pelvic irradiation [22, 23]. The risk factors of GSM include cigarette smoking and alcohol abuse, which are correlated with a reduction in oestrogen levels and an absence of vaginal childbirth [24]. Before the climacteric period, the vagina is composed of thick layers of healthy cells, and oestrogen encourages the growth and development of these cells; therefore, vaginal epithelium remains multi-layered, and vaginal walls are supple and elastic $[16,25]$. The vaginal epithelium is rich in glycogen, which is metabolised from lactobacilli in lactic acid, maintaining an acid $\mathrm{pH}$ and providing natural protection against infections. Furthermore, oestrogen levels allow vaginal secretions and lubrication through the production of acid mucopolysaccharides and hyaluronic acid, and optimise vaginal blood flow $[22,24]$. The progressive reduction in circulating oestrogen, which occurs following the cessation of ovarian function, induces various metabolic and tissue changes, which are most prominent in the genital tract due to its particular sensitivity to variations in sex hormone levels $[16,26]$. The consequences are a reduction in lubrication, vascular blood, and vaginal elasticity and an increased friability of the vaginal vault. The reduction in lactobacilli changes the vaginal environment to an alkaline $\mathrm{pH}$ of more than 5 [22, 24]. All these changes are responsible for the clinical manifestations of GSM, which may include genital symptoms of dryness, burning, and irritation; sexual symptoms of lack of lubrication, discomfort or pain, and impaired function; as well as urinary symptoms of urgency, dysuria, and recurrent urinary tract infections $[14,15$, 27, 28]. The diagnosis is clinical and is based on anamnesis and physical examination. The most common and bothersome symptom is vaginal dryness [29, 30], and common physical findings are pallor or erythema, labia minora resorption, tissue fragility, loss of vaginal rugae, urethral eversion or prolapse, and introital retraction [31]. Furthermore, a vaginal smear using Rakoff staining allows the evaluation of the Vaginal Maturity Index (VMI), which calculates the number of parabasal, intermediate, and superficial cells and reflects the maturation of the vaginal epithelium [22]. In addition, a vaginal $\mathrm{pH}>5$ may be useful in the diagnosis.

\section{The effects of genitourinary syndrome of menopause on quality of life, sexual function, and psychological well-being}

Female sexual dysfunction (FSD) is defined as a disorder including female sexual interest/arousal disorder, orgasmic disorder, and genito-pelvic pain/penetration disorders [32]. The aetiology of these problem is multifactorial, involving advanced age, chronic diseases, psychological factors, medications, menopause, history of operative vaginal delivery, gynaecological surgery, urinary incontinence, gynaecological cancer, and infertility [2, 33-44].

The risk of sexual dysfunction for menopausal women is greater in cases of increasing age and decreasing oestrogen [45-48]. It has been estimated that 9.7 million American women aged 50 to 74 years suffer from FSD and report diminished vaginal lubrication, pain and discomfort with intercourse, decreased arousal, and difficulty achieving orgasm [45]. Aspects of sexual function that are affected by menopause include lubrication, orgasm, and sexual pain [46]. In fact, vaginal innervation seems to increase in response to lower oestrogen levels [31]. Furthermore, GSM also has an important psychological effect: VVA makes women feel older, uncomfortable, less feminine, frustrated, worried, anxious, and depressed [49]. Data from two large studies, VVIVA (Vaginal Health: Insights, Views, \& Attitudes) [50] and REVIVE (REal Women's Vlews of Treatment Options for Menopausal Vaginal ChangEs) [51], which were carried out by direct interviews with postmenopausal women, are extremely important to understand the multidimensionality of this disorder, how it can influence relationships, and, more generally, how it impacts quality of life (QoL). Other studies have demonstrated the association between sexual dysfunction and symptoms related to GSM by analysing the QoL of these women through the MEN-QoL (menopausal quality of life) questionnaire [52]. In some cases, GSM was found to affect even daily activities such as sleep and enjoyment of life [53], and a consistent number of women suffering from GSM are worried about the longterm effects on their relationships with their partners. Approximately $40 \%$ of them avoid intimacy because of 
painful sex or loss of sex drive and have difficulty discussing their discomfort with their partners [54].

Another important aspect of FSD is that it is often underdiagnosed and undertreated. Only about 60\% discuss this disorder with their health care provider (HCP), and the most common reported reasons for never discussing GSM symptoms with the HCP are the belief that this condition is a natural part of the aging phenomenon or that symptoms are not bothersome enough to warrant discussion [49]. To confirm the complexity of this phenomenon, studies that have evaluated the effects of treatments for FSD have highlighted how medications alone do not solve the problem and psychotherapies are often needed [55]. Furthermore, a recent meta-analysis demonstrated that $67.7 \%$ of the treatment effect for medications targeting FSD is accounted for by placebo [56]. These results reflect, on the one hand, the limits of some medications and, on the other, the need for a better knowledge of the mechanisms underlying FSD. Literature about the relationship between GSM and FSD is still controversial: several studies underline that sexual function is impaired by GSM but there are still few data on a significant association between these two conditions $[45,46]$. Therefore, further studies about this topic are needed.

\section{Intravaginal ultralow-concentration oestriol: pro and cons}

According to the North American Menopause Society (NAMS), women with GSM might use nonhormonal vaginal lubricants with sexual activity, long-acting vaginal moisturisers several times a week, and regular sexual activity; these are a first-line therapy. Women who will not obtain any benefit from these methods are candidates for low-dose vaginal oestrogen therapy, and if this also fails, the final step is the use of transdermal and oral hormones, including oral ospemifene [16]. Recommendations from 2017 suggests that low-dose vaginal oestrogen preparations are preferred in women with GSM, whereas non-oestrogen therapies that improve these kinds of symptoms include ospemifene and intravaginal DHEA. In those recommendations nonhormonal therapies are recommended for women with breast or endometrial cancers or those with high risk of such cancers [57]. The updated NAMS recommendations state that hormonal therapy is the most effective for GSM and vasomotor syndrome. Hormone therapy should be individually selected according to patients' personal preferences, health risks, as well as time since menopause. In patients after menopause, who suffer from isolated genitourinary symptoms, low-dose vaginal oestrogen therapy is recommended as the gold standard [57]. These recommendations are based on publications confirming the beneficial effect of local oestrogen therapy on the restoration of vaginal anat- omy and environment; however, the data taken into account are still qualified as low-quality evidence [58].

For women with moderate to severe vulvovaginal symptoms, who do not benefit from the use of lubricants and moisturisers, oestrogen therapy is generally recommended as a therapeutic standard [46]. Oestradiol is the predominant oestrogen produced by the ovaries in premenopausal women. It is oxidised to oestrone and both oestradiol and oestrone can be converted to oestriol by the liver. Although oestriol bioavailability is higher than oestradiol because of its lower affinity for the sex hormone binding protein [59], oestriol has lower oestrogenic potency than oestradiol (ranging from $1: 10$ to $1: 100$ ) [60] and greater relative affinity for oestrogen receptor- $\beta$ than for oestrogen receptor- $\alpha$, thus minimising extravaginal effects [61]. For this reason, a sequential progesterone for endometrial protection can be omitted [59].

Oestrogen can be administered in two main ways: orally and transdermally (patches, gel, spray) [62]. It is known that 0.5-1 mg intravaginal oestriol is well absorbed by an atrophic epithelium, and it is equivalent to oral doses of 8-12 mg [63]. Furthermore, oral oestriol administration is associated with entero-hepatic recirculation with prolonged exposure, whereas only $20 \%$ of oestriol applied intravaginally reaches the circulation [59]. Intravaginal oestriol improves symptoms of GSM, sexual health, and, more generally, women's QoL [64]. This improvement is confirmed by objective findings: reduction in VVA, changes in the vaginal environment, lowered $\mathrm{pH}$, improvement in pap smear and colposcopic parameters and increased VMI. Intravaginal oestriol is also effective on the urinary tract and it has been shown to improve symptoms and urodynamic parameters even in overactive bladder [9].

Currently, the lowest local dose of oestrogen for the shortest period may be prescribed to women experiencing vaginal symptoms [65]. In fact, a new ultralow-dose oestriol vaginal gel formulation $(0.005 \%$ oestriol vaginal gel), which significantly enhances oestriol delivery to vaginal tissue, compared with existing formulations, has been developed, thus allowing the use of much lower doses of oestriol to treat vaginal atrophy [9]. Several studies have reported satisfactory results with ultralow doses of intravaginal oestriol: as little as $0.03 \mathrm{mg}$ is sufficient to improve the clinical manifestations of GSM [64, 66-69]. Intravaginal oestriol can be applied through pessaries [66, 67], gel, or tablets, and the most common regimen is a daily application for 2-4 weeks followed by a maintenance of two or three applications per week for 2-6 months $[64,68,69]$. A combination of $0.03 \mathrm{mg}$ intravaginal oestriol and lactobacilli and/or pelvic floor rehabilitation has yielded positive results, demonstrating a further improvement in oestriol benefits with the association of non-pharmacological therapies [64, 65, $68,70]$. However, the main concerns regarding oestro- 
gen administration are side-effects, although few have been observed for intravaginal oestriol, and those that have are mainly local: irritation, burning sensation, itching, and leucorrhoea [71]. Furthermore, some studies have shown, on the basis of blood concentrations, that the profile for oestriol is safe because of its very low systemic bioavailability $[66,69]$, and no correlations have been found between intravaginal oestriol administration and increased endometrial thickness [59, 72].

Among the major concerns of the use of local oestrogen therapy in GSM are patients with hormone receptor-positive breast cancer. Clinicians suspects that the hormones absorbed through the vaginal wall may stimulate cancer recurrence $[73,74]$. The available data are somehow unclear as the results from the studies in this matter are conflicting [75, 76]. According to Donders et al., the low-dose oestriol therapy in patients during aromatase inhibitor treatment suffering from GSM-related issues can be considered as safe and efficacious because this method of treatment does not increase oestradiol and oestrogen levels [68]. In summary, local oestrogen therapy in hormone receptor-positive breast cancer is not contraindicated; however, it seems that the best course of action is caution in the use of these agents and monitoring of serum levels using the best available methods [74]. Additional clinical trials are necessary for further conclusions and to establish treatment standards in these patients.

\section{Intravaginal dehydroepiandrosterone: pro and cons}

Many other drugs, at different doses, have been studied over the years for the treatment of the symptoms of GSM. A new approach to treating GSM in postmenopausal women is the intravaginal administration of dehydroepiandrosterone (DHEA). DHEA and its sulphate (DHEAS) are the most abundant circulating sex steroids found in women [77]. DHEA is mainly produced in the adrenal cortex [78] but also by the testes [79] and ovaries [80] and can be synthesised within the brain [81], whereas DHEAS is a unique secretory product of the adrenal zona reticularis [77]. It has been demonstrated that DHEA is metabolised in peripheral tissues first to androstenedione and then to oestradiol (E2) or testosterone where it elicits an oestrogen effect or an androgenic effect according to the mechanisms of intracrinology [82-84]. The secretion of DHEA decreases with age, with an average $60 \%$ decrease during menopause [85]. This reduction in the secretion of DHEA is associated with a parallel fall in the formation of oestrogens and androgens in peripheral target tissues, determining the most common symptoms and signs of menopause, including GSM $[85,86]$. A number of studies have shown that DHEA administered intravaginally over a 12-week period reduces vaginal $\mathrm{pH}$ and improves the VMI with a better physical appearance of the vagina from $86 \%$ to $121 \%$ over the placebo effect $[87,88]$. Moreover, recent data have underlined the benefits of the local intravaginal action of DHEA on QoL and all domains of sexual dysfunction, especially in the most bothersome symptoms (dyspareunia and vaginal dryness), with an improvement of $41.3 \%$ compared with placebo $[89,90]$. One study also showed that the treatment has a positive effect on their partners' opinion [91].

The most common intravaginal dosage for DHEA (also called prasterone) is $6.5 \mathrm{mg}$ daily for 12 weeks. Some studies have shown that a lower dosage does not yield the same results [83] and that it is also less effective if administered only twice a week as maintenance therapy [92]. The mechanism of intracrinology explains the local effect of DHEA as well as the results of several studies that have demonstrated an absence of increased blood oestrogen and testosterone levels after DHEA administration for up to 12 months [9395], which in turn means that side effects are almost absent: Labrie et al. reported vaginal discharge due to melting of the vehicle at body temperature in $6 \%$ of women during intravaginal DHEA administration [88]. Even the androgenic side-effects such as acne and hirsutism, which might arouse more concern, seem to be rarely associated with DHEA, and only when administered orally [83]. When Portman et al. analysed the effects of DHEA on endometrium through biopsies at the end of a 12-week intravaginal treatment, the results showed atrophic or inactive endometrium, confirming the local effect of DHEA and its safety [96]. Although there is some evidence to support the use of intravaginal DHEA for postmenopausal women with symptoms of vaginal atrophy, further studies are needed to confirm this.

\section{Ospemifene}

The above-mentioned compounds are at the backbone of the treatment of patients suffering from GSM. It seems, however, that an additional information about good alternatives cannot be omitted. Ospemifene is a novel selective oestrogen receptor modulator (SERM) acting similarly to an oestrogen on the vaginal epithelium, which was primarily developed to treat postmenopausal osteoporosis [97]. Ospemifene is mentioned in NAMS recommendations in some indications in women with GSM [16]. According to the recent publication by Bruyniks et al., the clinical effect of ospemifene in patients with GSM is similar or even better than that of topical vaginal oestrogens [98]. The important thing is that the safety profile of this SERM appears to be similar to that of locally applied oestrogens. The authors of this review highlight that one of the main differences between ospemifene and local oestrogen that should 
be taken into account is that they are recommended only in shortest possible duration, whereas ospemifene can be used for longer periods [98]. Biglia et al. indicated also that ospemifene might be proposed as a safe option for women with breast cancer, even if this point requires additional studies [99]. Due to the extent of ospemifene in menopause and GSM, this manuscript does not cover the subject matter as a whole.

\section{Conclusions}

There is still a great deal of uncertainty regarding the treatments for GSM. We analysed two of these treatments: both ultralow dose intravaginal oestriol and intravaginal DHEA are reported to improve symptoms, signs, and quality of life of women with GSM, and they are safe owing to their specific local effect. While the dosage and the administration of intravaginal DHEA are well defined, the literature on intravaginal oestriol is less uniform: different doses and times of administration are proposed with different possible combinations with other non-pharmacological therapies, although a more standardised treatment may be necessary. Furthermore, a comparison between oestriol and DHEA and a definition of the type of women who may benefit most from each treatment might be useful.

\section{Disclosure}

The authors report no conflict of interest.

\section{References}

1. Takahashi TA, Johnson KM. Menopause. Med Clin North Am 2015; 99 : 521-534.

2. Vitale SG, Caruso S, Rapisarda AMC, et al. Isoflavones, calcium, Vitamin $D$ and inulin improve quality of life, sexual function, body composition and metabolic parameters in menopausal women: Result from a prospective, randomized, placebo-controlled, parallel-group study. Prz Menopauzalny 2018; 17: 32-38.

3. Cianci A, Colacurci N, Paoletti AM, et al. Soy Isoflavones, Inulin, Calcium, and Vitamin D3 in post-menopausal hot flushes: An observational study. Clin Exp Obstet Gynecol 2015; 42: 743-745.

4. Szymański JK, Siekierski BP, Kajdy A, et al. Post-menopausal vulvovaginal atrophy - an overview of the current treatment options. Ginekol Pol 2018; 89: 40-47.

5. Cagnacci A, Palma F, Napolitano A, et al. Association between pelvic organ prolapse and climacteric symptoms in postmenopausal women. Maturitas 2017; 99: 73-78.

6. Erekson EA, Li F-Y, Martin DK, et al. Vulvovaginal symptoms prevalence in postmenopausal women and relationship to other menopausal symptoms and pelvic floor disorders. Menopause 2016; 23: 368-375.

7. Vitale SG, Caruso S, Rapisarda AMC, et al. Biocompatible porcine dermis graft to treat severe cystocele: impact on quality of life and sexuality. Arch Gynecol Obstet 2016; 293: 125-131.

8. Laganà AS, La Rosa VL, Rapisarda AMC, et al. Pelvic organ prolapse: The impact on quality of life and psychological well-being. J Psychosom Obstet Gynecol 2018; 39: 164-166.

9. Caruso S, Cianci S, Vitale SG, et al. Effects of ultralow topical estriol dose on vaginal health and quality of life in postmenopausal women who underwent surgical treatment for pelvic organ prolapse. Menopause 2017; 24: 900-907.

10. Wasenda EJ, Kamisan Atan I, Subramaniam N, Dietz HP. Pelvic organ prolapse: does hormone therapy use matter? Menopause 2017; 24: 1185-1189.

11. Castelo-Branco C, Cancelo MJ, Villero J, et al. Management of postmenopausal vaginal atrophy and atrophic vaginitis. Maturitas 2005; 52 (Suppl 1): S46-52.

12. Archer DF. Efficacy and tolerability of local estrogen therapy for urogenital atrophy. Menopause 2010; 17: 194-203.

13. Laganà AS, Vitale SG, Stojanovska L, et al. Preliminary results of a single-arm pilot study to assess the safety and efficacy of visnadine, prenylflavonoids and bovine colostrum in postmenopausal sexually active women affected by vulvovaginal atrophy. Maturitas 2018; 109: 78-80.

14. Portman DJ, Gass MLS, Kingsberg S, et al. Genitourinary syndrome of menopause: New terminology for vulvovaginal atrophy from the international society for the study of women's sexual health and the North American Menopause Society. Menopause 2014; 21: 1063-1068.

15. Farrell Am E. Genitourinary syndrome of menopause. Aust Fam Physician 2017; 46: 481-484.

16. Management of symptomatic vulvovaginal atrophy: 2013 position statement of the North American Menopause Society. Menopause 2013; 20: 888-902.

17. van Geelen JM, van de Weijer PH, Arnolds HT. Urogenital symptoms and resulting discomfort in non-institutionalized Dutch women aged 50-75 years. Int Urogynecol J Pelvic Floor Dysfunct 2000; 11: 9-14.

18. Stenberg A, Heimer G, Ulmsten U, et al. Prevalence of genitourinary and other climacteric symptoms in 61-year-old women. Maturitas 1996; 24 31-36.

19. Hodges AL, Holland AC, Dehn B, et al. Diagnosis and Treatment of Genitourinary Syndrome of Menopause. Nurs Womens Health 2018; 22 423-430.

20. Moral E, Delgado JL, Carmona F, et al. Genitourinary syndrome of menopause. Prevalence and quality of life in Spanish postmenopausal women. The GENISSE study. Climacteric 2018; 21: 167-173.

21. Shifren JL. Genitourinary Syndrome of Menopause. Clin Obstet Gynecol 2018; 61: 508-516.

22. Phillips NA, Bachmann GA. Genitourinary syndrome of menopause: Common problem, effective treatments. Cleve Clin J Med 2018; 85: 390 398.

23. Meczekalski B, Katulski K, Czyzyk A, et al. Functional hypothalamic amenorrhea and its influence on women's health. J Endocrinol Invest 2014; 37: 1049-1056.

24. Gandhi J, Chen A, Dagur G, et al. Genitourinary syndrome of menopause: an overview of clinical manifestations, pathophysiology, etiology, evaluation, and management. Am J Obstet Gynecol 2016; 215: 704-711.

25. Suckling J, Lethaby A, Kennedy R. Local oestrogen for vaginal atrophy in postmenopausal women. Cochrane Database Syst Rev 2006: CD001500.

26. Kingsberg S, Kellogg S, Krychman M. Treating dyspareunia caused by vaginal atrophy: a review of treatment options using vaginal estrogen therapy. Int J Womens Health 2010; 1: 105-111.

27. Patnaik SS, Laganà AS, Vitale SG, et al. Etiology, pathophysiology and biomarkers of interstitial cystitis/painful bladder syndrome. Arch Gynecol Obstet 2017; 295: 1341-1359.

28. Gardella B, lacobone AD, Porru D, et al. Effect of local estrogen therapy (LET) on urinary and sexual symptoms in premenopausal women with interstitial cystitis/bladder pain syndrome (IC/BPS). Gynecol Endocrinol 2015; 31: 828-832.

29. Palma F, Xholli A, Cagnacci A, et al. The most bothersome symptom of vaginal atrophy: Evidence from the observational AGATA study. Maturitas 2018; 108: 18-23.

30. Cagnacci A, Xholli A, Sclauzero M, et al. Vaginal atrophy across the menopausal age: results from the ANGEL study. Climacteric 2019; 22: 85-89.

31. Mitchell CM, Waetjen LE. Genitourinary Changes with Aging. Obstet Gynecol Clin North Am 2018; 45: 737-750.

32. American Psychiatric Association. Diagnostic and Statistical Manual of Mental Disorders, $5^{\text {th }}$ ed. (DSM-5). American Psychiatric Association, 2013.

33. Graziottin A. Sexual function in women with gynaecologic cancer. A review. Ital J Gynaecol Obstet 2001; 13: 61-68. 
34. Athanasiou S, Grigoriadis T, Chalabalaki A, et al. Pelvic organ prolapse contributes to sexual dysfunction: a cross-sectional study. Acta Obstet Gynecol Scand 2012; 91: 704-709.

35. Pérez-Tomás C, Gómez-Pérez L, Romero-Maroto J, et al. Sexual Quality of Life After Treatment of Stress Urinary Incontinence With Adjustable Tension-free Mesh System in Women Who Were Sexually Active Before Surgery. Urology 2018; 115: 76-81.

36. Sen I, Onaran M, Tan MO, et al. Evaluation of sexual function in women with overactive bladder syndrome. Urol Int 2007; 78: 112-115.

37. Carter J, Stabile C, Gunn A, et al. The Physical Consequences of Gynecologic Cancer Surgery and Their Impact on Sexual, Emotional, and Quality of Life Issues. J Sex Med 2013; 10: 21-34.

38. Vitale SG, La Rosa VL, Rapisarda AMC, et al. Psychology of infertility and assisted reproductive treatment: the Italian situation. J Psychosom Obstet Gynecol 2017; 38: 1-3.

39. Sarikaya S, Yildiz FG, Senocak C, et al. Urinary incontinence as a cause of depression and sexual dysfunction: Questionnaire-based study. Rev Int Androl 2018: S1698-031X(18)30082-7.

40. Caruso S, Cianci S, Vitale SG, et al. Sexual function and quality of life of women adopting the levonorgestrel-releasing intrauterine system (LNG-IUS 13.5 mg) after abortion for unintended pregnancy. Eur J Contracept Reprod Health Care 2018; 23: 24-31.

41. Vitale SG, Laganà AS, Noventa M, et al. Transvaginal Bilateral Sacrospinous Fixation after Second Recurrence of Vaginal Vault Prolapse: Ef ficacy and Impact on Quality of Life and Sexuality. Biomed Res Int 2018; 2018: 5727165.

42. Ferrero S, Abbamonte LH, Giordano M, et al. Uterine myomas, dyspareunia, and sexual function. Fertil Steril 2006; 86: 1504-1510.

43. Ryann Louie A, Armstrong JA, Findeiss LK, et al. Comparison of Sexual Dysfunction Using the Female Sexual Function Index following Surgical Treatments for Uterine Fibroids. Case Rep Obstet Gynecol 2012; 2012: 368136.

44. Vitale SG, La Rosa VL, Rapisarda AMC, et al. Sexual life in women with stress urinary incontinence. Oman Med J 2017; 32: 174-175.

45. Levine KB, Williams RE, Hartmann KE. Vulvovaginal atrophy is strongly associated with female sexual dysfunction among sexually active postmenopausal women. Menopause 2008; 15: 661-666.

46. Murina F, Graziottin A, Felice R, et al. Coital pain in the elderly: could a low dose estriol gel thrill the vulvar vestibule? Eur J Obstet Gynecol Reprod Biol 2016; 207: 121-124.

47. Mollaioli D, Lin LT, Shah M, et al. Multidisciplinary management of sexual quality of life among menopausal women with urogynecological complains. Ital J Gynaecol Obstet 2018; 30: 15-20.

48. La Rosa VL, Sapia F, Salvaggio C, et al. Quality of life and sexual function in women with genitourinary syndrome of menopause (GSM): effectiveness of local therapy with ultralow-concentration estriol vaginal gel. Ita J Gynaecol Obstet 2018; 30: 7-13.

49. Nappi RE, Particco M, Biglia N, et al. Attitudes and perceptions towards vulvar and vaginal atrophy in Italian post-menopausal women: Evidence from the European REVIVE survey. Maturitas 2016; 91: 74-80.

50. Simon JA, Kokot-Kierepa M, Goldstein J, et al. Vaginal health in the United States: results from the Vaginal Health: Insights, Views \& Attitudes survey. Menopause 2013; 20: 1043-1048.

51. Kingsberg SA, Wysocki S, Magnus L, et al. Vulvar and vaginal atrophy in postmenopausal women: findings from the REVIVE (REal Women's Vlews of Treatment Options for Menopausal Vaginal ChangEs) survey. J Sex Med 2013; 10: 1790-1799.

52. Pinkerton JAV, Bushmakin AG, Komm BS, et al. Relationship between changes in vulvar-vaginal atrophy and changes in sexual functioning. Maturitas 2017; 100: 57-63.

53. Chua Y, Limpaphayom KK, Cheng B, et al. Genitourinary syndrome of menopause in five Asian countries: results from the Pan-Asian REVIVE survey. Climacteric 2017; 20: 367-373.

54. Nappi RE, Kingsberg S, Maamari R, et al. The CLOSER (CLarifying Vaginal Atrophy's Impact On SEx and Relationships) survey: implications of vaginal discomfort in postmenopausal women and in male partners. J Sex Med 2013; 10: 2232-2241.

55. Weinberger JM, Houman J, Caron AT, Anger J. Female Sexual Dysfunction: A Systematic Review of Outcomes Across Various Treatment Modalities. Sex Med Rev 2019; 7: 223-250.
56. Weinberger JM, Houman J, Caron AT, et al. Female Sexual Dysfunction and the Placebo Effect: A Meta-analysis. Obstet Gynecol 2018; 132: 453-458.

57. The NAMS 2017 Hormone Therapy Position Statement Advisory Panel. The 2017 hormone therapy position statement of The North American Menopause Society. Menopause 2017; 24: 728-753.

58. Lethaby A, Ayeleke RO, Roberts H. Local oestrogen for vaginal atrophy in postmenopausal women. Cochrane Database Syst Rev 2016: CD001500.

59. Ali ES, Mangold C, Peiris AN. Estriol: emerging clinical benefits. Menopause 2017; 24: 1081-1085.

60. Bachmann GA, Nevadunsky NS. Diagnosis and treatment of atrophic vaginitis. Am Fam Physician 2000; 61: 3090-3096.

61. North American Menopause Society. The role of local vaginal estrogen for treatment of vaginal atrophy in postmenopausal women: 2007 position statement of The North American Menopause Society. Menopause 2007; 14: 355-369; quiz 370-371.

62. Krause M, Wheeler TL, Snyder TE, et al. Local Effects of Vaginally Administered Estrogen Therapy: A Review. J Pelvic Med Surg 2009; 15: 105-114.

63. Mattsson LÅ, Cullberg G. Vaginal absorption of two estriol preparations: A comparative study in postmenopausal women. Acta Obstet Gynecol Scand 1983; 62: 393-396.

64. Buchholz S, Mögele M, Lintermans A, et al. Vaginal estriol-lactobacilli combination and quality of life in endocrine-treated breast cancer. Climacteric 2015; 18: 252-259.

65. Jaisamrarn U, Triratanachat S, Chaikittisilpa S, et al. Ultra-low-dose estriol and lactobacilli in the local treatment of postmenopausal vaginal atrophy. Climacteric 2013; 16: 347-355.

66. Buhling KJ, Eydeler U, Borregaard S, et al. Systemic bioavailability of estriol following single and repeated vaginal administration of $0.03 \mathrm{mg}$ estriol containing pessaries. Arzneimittelforschung 2012; 62: 378-383.

67. Griesser H, Skonietzki S, Fischer T, et al. Low dose estriol pessaries for the treatment of vaginal atrophy: a double-blind placebo-controlled trial investigating the efficacy of pessaries containing $0.2 \mathrm{mg}$ and $0.03 \mathrm{mg}$ estriol. Maturitas 2012; 71: 360-368

68. Donders G, Neven P, Moegele M, et al. Ultra-low-dose estriol and Lactobacillus acidophilus vaginal tablets (Gynoflor(®)) for vaginal atrophy in postmenopausal breast cancer patients on aromatase inhibitors: pharmacokinetic, safety, and efficacy phase I clinical study. Breast Cancer Res Treat 2014; 145: 371-379.

69. Delgado JL, Estevez J, Radicioni M, et al. Pharmacokinetics and preliminary efficacy of two vaginal gel formulations of ultra-low-dose estriol in postmenopausal women. Climacteric 2016; 19: 172-180.

70. Capobianco G, Wenger JM, Meloni GB, et al. Triple therapy with Lactobacilli acidophili, estriol plus pelvic floor rehabilitation for symptoms of urogenital aging in postmenopausal women. Arch Gynecol Obstet 2014; 289: 601-608.

71. Rueda C, Osorio AM, Avellaneda AC, et al. The efficacy and safety of estriol to treat vulvovaginal atrophy in postmenopausal women: a systematic literature review. Climacteric 2017; 20: 321-330.

72. Mueck AO, Ruan X, Prasauskas V, et al. Treatment of vaginal atrophy with estriol and lactobacilli combination: a clinical review. Climacteric 2018; 21: 140-147.

73. Bakken K, Fournier A, Lund E, et al. Menopausal hormone therapy and breast cancer risk: impact of different treatments. The European Prospective Investigation into Cancer and Nutrition. Int J Cancer 2011; 128: 144-156.

74. Sulaica E, Han T, Wang W, et al. Vaginal estrogen products in hormone receptor-positive breast cancer patients on aromatase inhibitor therapy. Breast Cancer Res Treat 2016; 157: 203-210.

75. von Schoultz E, Rutqvist LE, Stockholm Breast Cancer Study Group. Menopausal hormone therapy after breast cancer: the Stockholm randomized trial. J Natl Cancer Inst 2005; 97: 533-535.

76. Holmberg L, Iversen O-E, Rudenstam CM, et al. Increased risk of recurrence after hormone replacement therapy in breast cancer survivors. J Natl Cancer Inst 2008; 100: 475-482.

77. Panjari M, Davis SR. Vaginal DHEA to treat menopause related atrophy: a review of the evidence. Maturitas 2011; 70: 22-25. 
78. Symington T, Duguid WP, Davidson JN. Effect of exogenous corticotropin on the histochemical pattern of the human adrenal cortex and a comparison with the changes during stress. J Clin Endocrinol Metab 1956; 16: 580-598.

79. Hall PF, Sozer CC, Eik-Nes KB. Formation of Dehydroepiandrosterone During in Vivo and in Vitro Biosynthesis of Testosterone by Testicular Tissue. Endocrinology 1964; 74: 35-43.

80. Aakvaag A, Hagen AA, Eik-Nes KB. Biosynthesis in vivo of testosterone and $\triangle 4$-androstenedione from dehydroepiandrosterone-sodium sulfate by the canine testis and ovary. Biochim Biophys Acta 1964; 86: 622-627.

81. Plassart-Schiess E, Baulieu EE. Neurosteroids: recent findings. Brain Res Brain Res Rev 2001; 37: 133-140.

82. Labrie F, Luu-The V, Labrie C, Simard J. DHEA and its transformation into androgens and estrogens in peripheral target tissues: intracrinology. Front Neuroendocrinol 2001; 22: 185-212.

83. Archer DF. Dehydroepiandrosterone intra vaginal administration for the management of postmenopausal vulvovaginal atrophy. J Steroid Biochem Mol Biol 2015; 145: 139-143.

84. Chern CU, Tsui KH, Vitale SG, et al. Dehydroepiandrosterone (DHEA) supplementation improves in vitro fertilization outcomes of poor ovarian responders, especially in women with low serum concentration of DHEA-S: a retrospective cohort study. Reprod Biol Endocrinol 2018; 16: 90.

85. Labrie F, Bélanger A, Cusan L, et al. Marked decline in serum concentrations of adrenal C19 sex steroid precursors and conjugated androgen metabolites during aging. J Clin Endocrinol Metab 1997; 82: 2396-2402.

86. Labrie F, Bélanger A, Bélanger P, et al. Androgen glucuronides, instead of testosterone, as the new markers of androgenic activity in women. J Steroid Biochem Mol Biol 2006; 99: 182-188.

87. Labrie F, Archer D, Bouchard C, et al. Intravaginal dehydroepiandrosterone (Prasterone), a physiological and highly efficient treatment of vaginal atrophy. Menopause 2009; 16: 907-922.

88. Labrie F, Archer DF, Koltun W, et al. Efficacy of intravaginal dehydroepiandrosterone (DHEA) on moderate to severe dyspareunia and vaginal dryness, symptoms of vulvovaginal atrophy, and of the genitourinary syndrome of menopause. Menopause 2018; 25: 1339-1353.

89. Labrie F, Archer D, Bouchard C, et al. Effect of intravaginal dehydroepiandrosterone (Prasterone) on libido and sexual dysfunction in postmenopausal women. Menopause 2009; 16: 923-931.

90. Labrie F, Archer D, Bouchard C, et al. Lack of influence of dyspareunia on the beneficial effect of intravaginal prasterone (dehydroepiandrosterone, DHEA) on sexual dysfunction in postmenopausal women. J Sex Med 2014; 11: 1766-1785.

91. Labrie F, Montesino M, Archer DF, et al. Influence of treatment of vulvovaginal atrophy with intravaginal prasterone on the male partner. Climacteric 2015; 18: 817-825.

92. Bouchard C, Labrie F, Archer DF, et al. Decreased efficacy of twice-weekly intravaginal dehydroepiandrosterone on vulvovaginal atrophy. Climacteric 2015; 18: 590-607.

93. Labrie F, Martel C, Bérubé R, et al. Intravaginal prasterone (DHEA) provides local action without clinically significant changes in serum concentrations of estrogens or androgens. J Steroid Biochem Mol Biol 2013; 138: 359-367.

94. Ke Y, Gonthier R, Simard J-N, et al. Serum steroids remain within the same normal postmenopausal values during 12-month intravaginal 0.50\% DHEA. Horm Mol Biol Clin Investig 2015; 24: 117-129.

95. Martel C, Labrie F, Archer DF, et al. Serum steroid concentrations remain within normal postmenopausal values in women receiving daily $6.5 \mathrm{mg}$ intravaginal prasterone for 12 weeks. J Steroid Biochem Mol Biol 2016; 159: 142-153.

96. Portman DJ, Labrie F, Archer DF, et al. Lack of effect of intravaginal dehydroepiandrosterone (DHEA, prasterone) on the endometrium in postmenopausal women. Menopause 2015; 22: 1289-1295.

97. Rutanen E-M, Heikkinen J, Halonen K, et al. Effects of ospemifene, a novel SERM, on hormones, genital tract, climacteric symptoms, and quality of life in postmenopausal women: a double-blind, randomized trial. Menopause 2003; 10: 433-439.
98. Bruyniks N, Biglia N, Palacios S, et al. Systematic indirect comparison of ospemifene versus local estrogens for vulvar and vaginal atrophy. Climacteric 2017; 20: 195-204.

99. Biglia N, Bounous VE, Sgro LG, et al. Genitourinary Syndrome of Menopause in Breast Cancer Survivors: Are We Facing New and Safe Hopes? Clin Breast Cancer 2015; 15: 413-420. 